
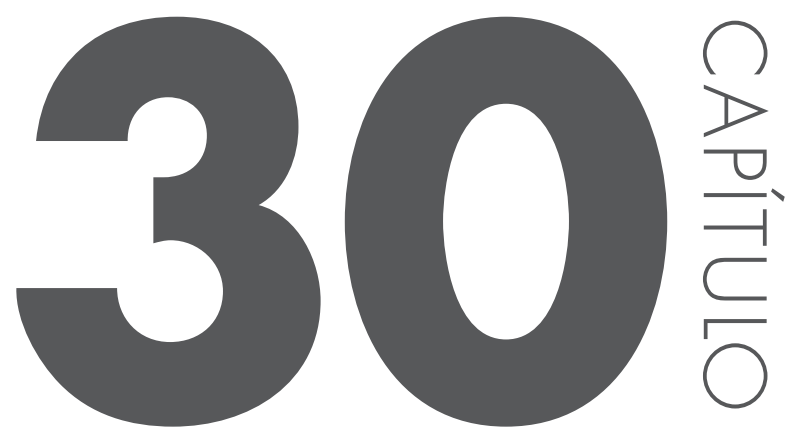

\title{
BASES DA FISIOPATOLOCIA DA DIARREIA (THE PATHOPHYSIOLOGY OF DIARRHEA)
}

Cirle Alcantara Warren

\subsection{INTRODUCTION}

Diarrhea is one of the most common complaints of patients seeking medical attention. It is commonly described as increased liquidity or decreased consistency ("loose or watery") of stool ${ }^{1,2}$. Other authors have defined diarrhea in terms of increased in stool frequency or fecal weight but in general, increased in defecation alone is not regarded as diarrhea and patients may have loose or watery stool with normal weight. The differential diagnosis for diarrhea is broad and the basic mechanism involved depends on the underlying etiologic cause. Understanding 
the basic physiology of the gastrointestinal tract is essential in the understanding of the mechanisms of gut dysfunction and the development of diarrhea.

The gastrointestinal tract is a delicate balance of 4 basic physiologic functions: secretion, absorption, barrier function and motility. All of these processes aim to facilitate extraction of nutrients or needed substances from food and excretion of excess, refuse and toxic materials. Intestinal absorption of water is crucial to maintain hydration for normal bodily functions. Moreover, the intestinal epithelium undergoes constant regeneration. As discussed in Chapter 16, intestinal cell proliferation occurs in the crypt, which actively supplies the sloughing enterocytes at the villus, where most absorption occurs. The entire intestinal epithelium may be replaced in 2-3 days.

As discussed in Chapter 16, everyday, the intestinal tract accommodates around 9 liters of water, of which 7 liters come from mucosal and glandular secretions ${ }^{3}$. Seventy eight percent of the water is absorbed in the small intestine and $21 \%$ are absorbed in the colon. Only $100 \mathrm{ml}$ is left in the stool for excretion. Secretion, mostly occurring in crypt cells, and absorption, mostly occurring in the villi, are usually facilitated by various ion transport mechanisms that are regulated by the enteric nervous, endocrine, and immune systems. Small intestinal pathology tends to cause voluminous, watery diarrhea as most secretion and absorption occur in this site. Large intestinal pathology tends to present with mucoid, bloody, inflammatory or scanty diarrhea. There are different ways on how the physiologic balance in the gastrointestinal tract could be disturbed and cause diarrhea.

\subsection{SECRETORY DIARRHEA}

Case 1: A 5 year-old boy presents with diarrhea with stool described as watery and with bowel movements occurring 5 times a day. His eyeballs are mildly sunken. He does not have any fever nor abdominal pain on examination. His mother claims that he has not eaten anything unusual and that since 3 days ago when his diarrhea started, she has been giving him a herbal medicine that seems to be now making his stool more formed.

"Loose" bowel movement or "watery" diarrhea suggests decrease amount of solute relative to water in the stool. Water transport, which occurs in conjunction with the movement of ions and solutes across the cell membrane, is thought to be facilitated by water channels called aquaporins ${ }^{4}$. It is still unclear how diarrheagenic pathogens directly affect these water channels but presumably, movement of water across the intestinal epithelium is passive as it follows the transport of ions or solutes through channels that may be regulated by several factors. 
Thus, increased in ion transport towards the luminal side (secretion) or decreased movement of ion or solutes towards the basal side (absorption) of the epithelium increases water content of the stool. Infectious agents mediate diarrhea either by release of toxins that alter transport across ion channels, by directly modifying the structure and function of the absorptive microvilli or compromising the integrity of the epithelial barrier ${ }^{5}$.

\subsubsection{INCREASED ION SECRETION}

Chloride secretion predominantly occurs in the intestinal crypts thru Clchannels. Cl- transport through $\mathrm{Cl}$ - channels is driven by the ion gradient generated by energy-dependent (Na-K-ATPase) and -independent ( $\mathrm{Na}-\mathrm{K}-\mathrm{Cl}$ co-transporter) ion channels located in the basolateral surface of intestinal epithelial cells (IECs) (Figure 30.1 $)^{6}$. Cytic fibrosis transmembrane regulator $(\mathrm{CFTR})^{7}$ and calcium dependent $\mathrm{Cl}$ channels $(\mathrm{CaCC})^{8}$ are 2 known chloride channels. Enterotoxins from either bacterial or viral pathogens- commonly causing secretory or watery diarrhea, alter these transport channels. The cholera toxin (CT) of Vibrio cholerae, upon binding to membrane receptor, GM1, is transported intracellularly. It, then, activates adenylate cyclase causing generation of cAMP. CAMP activates protein kinase A, which in turn, activates CFTR resulting to translocation of the ion channel to the enterocyte surface and consequently, to increase in chloride secretion. E.coli heat labile toxin LT, being structurally and functionally homologous to CT, causes the same effect ${ }^{9}$. Upregulation and activation of CFTRs can also be accomplished by E. coli heat stable toxin, STa, through binding to transmembrane guanylate cyclases (GC) in the brush border of the intestinal epithelial cells ${ }^{10,11}$. These GCs are located mostly in the apical, but are also found in the basolateral aspects of the IEC. Increase in cGMP activates protein kinase G, which like PKA, directly phosphorylates CFTR to stimulate secretion ${ }^{12}$. Endogenous peptides, guanylin and uroguanylin, can also bind and activate GCs.

The CaCC pathway is less understood. The thermostable direct haemolysin (TDH) of Vibrio parahemolyticus activates this chloride channel ${ }^{13}$. Any condition that increases intracellular calcium concentration, may presumably cause activation of CaCCs. Rotavirus, the most common cause of diarrhea in children, causes increased intracellular $\mathrm{Ca}^{++}$mediated by NSP4 enterotoxin, which in turn induces $\mathrm{Cl}^{-}$secretion ${ }^{14}$. Prostaglandins, generated during inflammatory conditions, e.g. inflammatory bowel disease or enteric infections, by activating submucosal enteric neurons, causes secondary increases in neurotransmitters, vasoactive intestinal peptide (VIP), acetylcholamine (Ach), and substance $\mathrm{P}^{15}$. VIP and Ach, in turn, induce $\mathrm{Cl}^{-}$secretion via cAMP and $\mathrm{Ca}^{++}$-dependent mecha- 
nisms. Substance P may directly activate epithelial cells and induce $\mathrm{Cl}^{-}$secretion. Of note, CT-induced secretion has also been additionally attributed to release of prostaglandins ${ }^{16}$.

\section{$\mathrm{Cl}^{-}$}
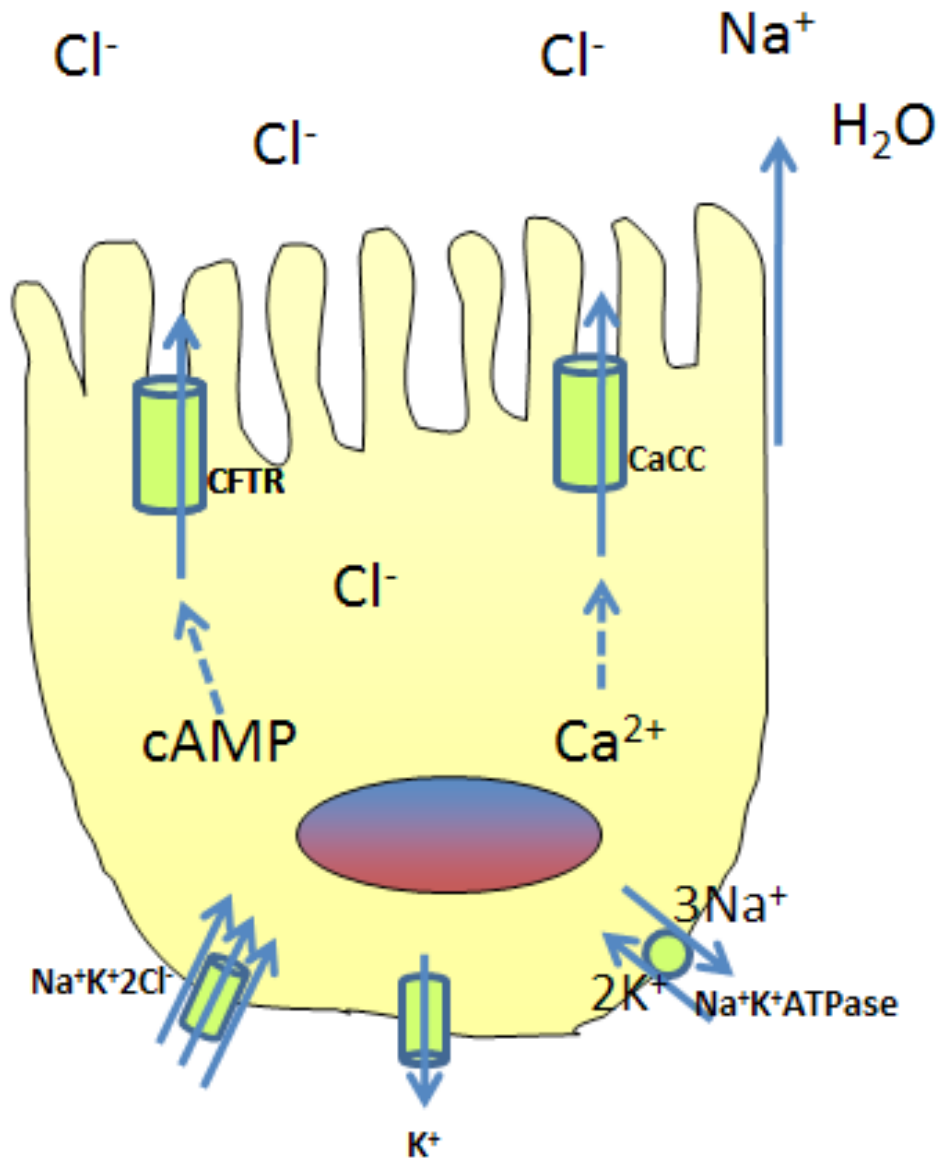

Figure 30.1 Increased Ion Secretion. - Under physiologic condition, the movement of chloride $(\mathrm{Cl})$ across the apical cell is generated by the intracellular resting negative potential from the activity of ion transport channels at the basolateral membrane ${ }^{53}$. Cyclic AMP and calcium $\left(\mathrm{Ca}^{2+}\right)$ are the main signaling molecules that activate the chloride channels, cystic fibrosis transmembrane regulator (CFTR) and $\mathrm{Ca}^{2+}$ dependent chloride channel (CaCC). Any condition that causes elevated CAMP or $\mathrm{Ca}^{2+}$ may potentially augment $\mathrm{Cl}$ secretion, which is followed by $\mathrm{Na}^{+}$secretion with the osmotic gradient generated pulling water towards the lumen. 


\subsubsection{IMPAIRED ION OR SOLUTE ABSORPTION}

Impairment in channels mediating solute or ion absorption is another mechanism for diarrhea (Figure 30.2). The $\mathrm{Cl}^{-} / \mathrm{OH}^{-}$exchanger, down regulated in adenoma (DRA) is located in the apical side of the enterocytes. This ion channel allows for transport of $\mathrm{Cl}^{-}$from the apical to the basolateral side of the epithelium. Lifelong diarrhea is observed in congenital chloride diarrhea from a recessive mutation resulting to decreased amounts of DRAs ${ }^{17}$. Enteric pathogens that cause blunting of the apical microvilli (or brush border) effectively decrease the surface $\mathrm{Cl}^{-} / \mathrm{OH}$, as well as other ion exchangers, thus inhibiting $\mathrm{Cl}^{-}$absorption. Enteropathogenic E. coli (EPEC) decreases the cell surface DRAs by attaching to the intestinal epithelial cells and cause effacement of the brush border microvilli ${ }^{18}$. This "attachment and effacement" process is thought to cause internalization of DRAs. The parasite Cryptosporidium spp, known to cause persistent diarrhea in malnourished children and immunocompromised adults, may also mediate diarrhea by attaching to the microvilli and cause disruption of the cell surface with its accompanying ion channels.

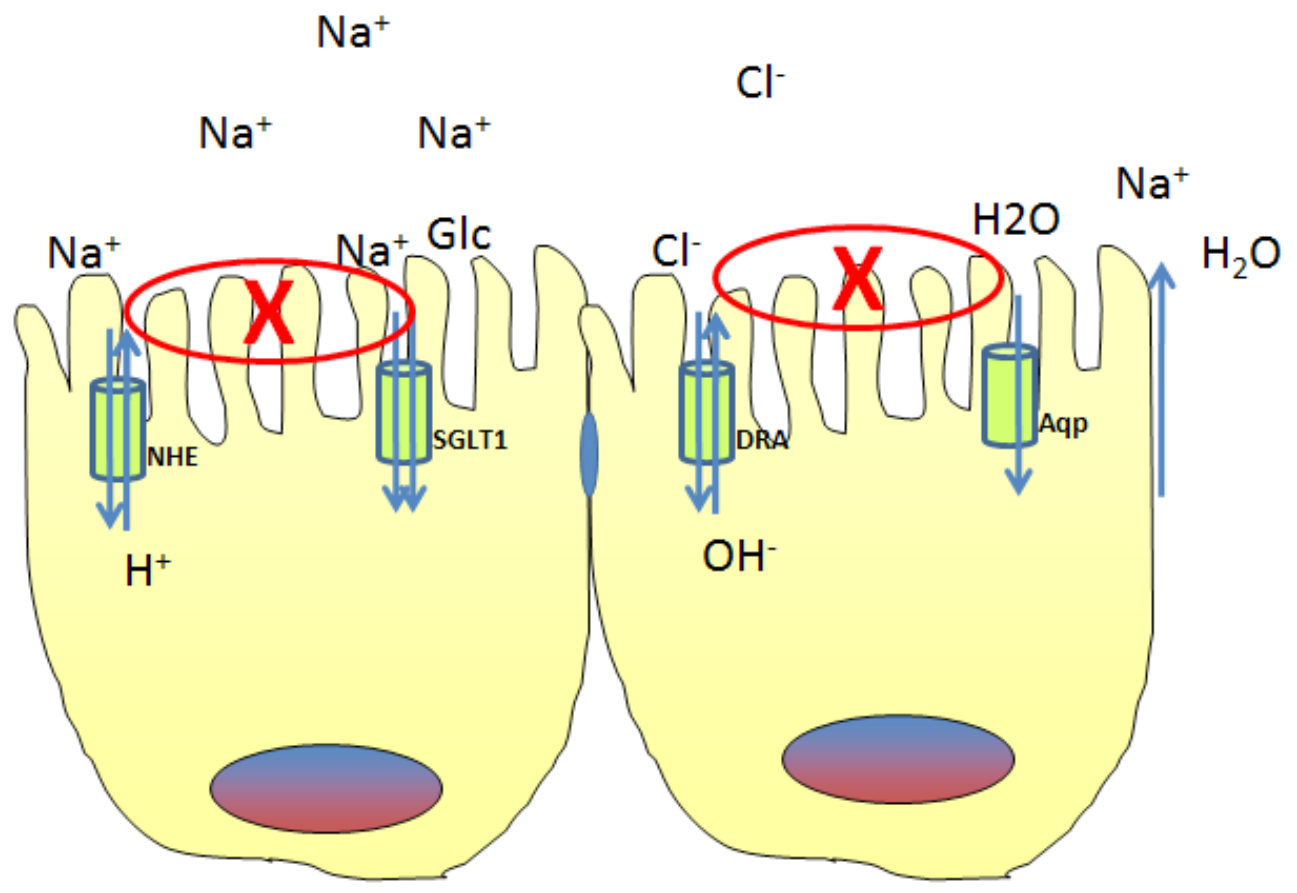

Figure 30.2 - Decreased lon or Solute Absorption. The apical surface of the enterocytes has ion channels that mediate transport of ions and water. Conditions that cause effacement or disruption of the microvilli can lead to displacement of these channels, decreasing the absorption, thereby increasing intraluminal solute and water content. 
Intestinal $\mathrm{Na}^{+}$absorption is accomplished primarily through $\mathrm{Na}^{+} / \mathrm{H}^{-}$exchangers (NHEs). Cyclic AMP, cGMP and elevated $\mathrm{Ca}^{2+}$, as well as neuroendocrine substances, inhibit NHEs. Cholera toxin and LT, through their effect on cAMP, also cause decrease $\mathrm{Na}^{+} / \mathrm{H}^{+}$activity. Other conditions that increase intracellular cAMP levels may, while increasing $\mathrm{Cl}^{-}$secretion through CFTR can also decrease $\mathrm{Na}^{+}$absorption through NHEs.

EPEC, through its secreted proteins, causes destruction of microvilli and consequently, decreased surface area available for channels for $\mathrm{Na}^{+}$uptake, such as, NHEs. Moreover, EPEC also reduces the activity of $\mathrm{Na}$ /glucose cotransporter SGLT1 ${ }^{19}$. SGLT1 promotes $\mathrm{Na}^{+}$absorption in the presence of glucose only. Because of its effect on SGLT1, diarrhea secondary to EPEC, unlike cholera toxin, is not as responsive to oral rehydration, which rely on glucose to drive $\mathrm{Na}^{+}$(and subsequent water) absorption ${ }^{20}$.

Pathogens affecting the absorptive microvilli can also cause maldigestion of sugars and proteins secondary to decreased brush border enzymes. Rotavirus has recently been reported to impair the biosynthesis of a brush border peptidase in a human intestinal cell line ${ }^{21}$.

\subsection{INFLAMMATORY DIARRHEA}

Case 2. A 70 year old lady was brought to the emergency room with low grade fever and confusion. She has a recent history of urinary tract infection for which she was treated with a week-long course of antibiotics. During examination, she was noted to have decreased bowel sounds. She grimaced upon palpation of her left lower abdomen. Stool sample was reported to be positive for WBCs.

Injury to the epithelial barrier, cell death and recruitment of inflammatory cells are the pathohistologic hallmarks of inflammatory diarrhea. These changes can be due to direct invation of the enterocytes by bacteria or by the internalization of bacterial toxins or products that affect the cytoskeleton, incite an inflammatory cascade and induce apoptosis (Figure 30.3). The increased permeability leads to transport of ions, solutes, water, bacteria and toxins across the epithelium. Local and systemic inflammatory reactions are elicited. Stool becomes positive for leukocytes or even blood, in some cases. The patient may have abdominal pain from the inflamed intestines, increased WBC in the blood (leukocytosis) and fever. 


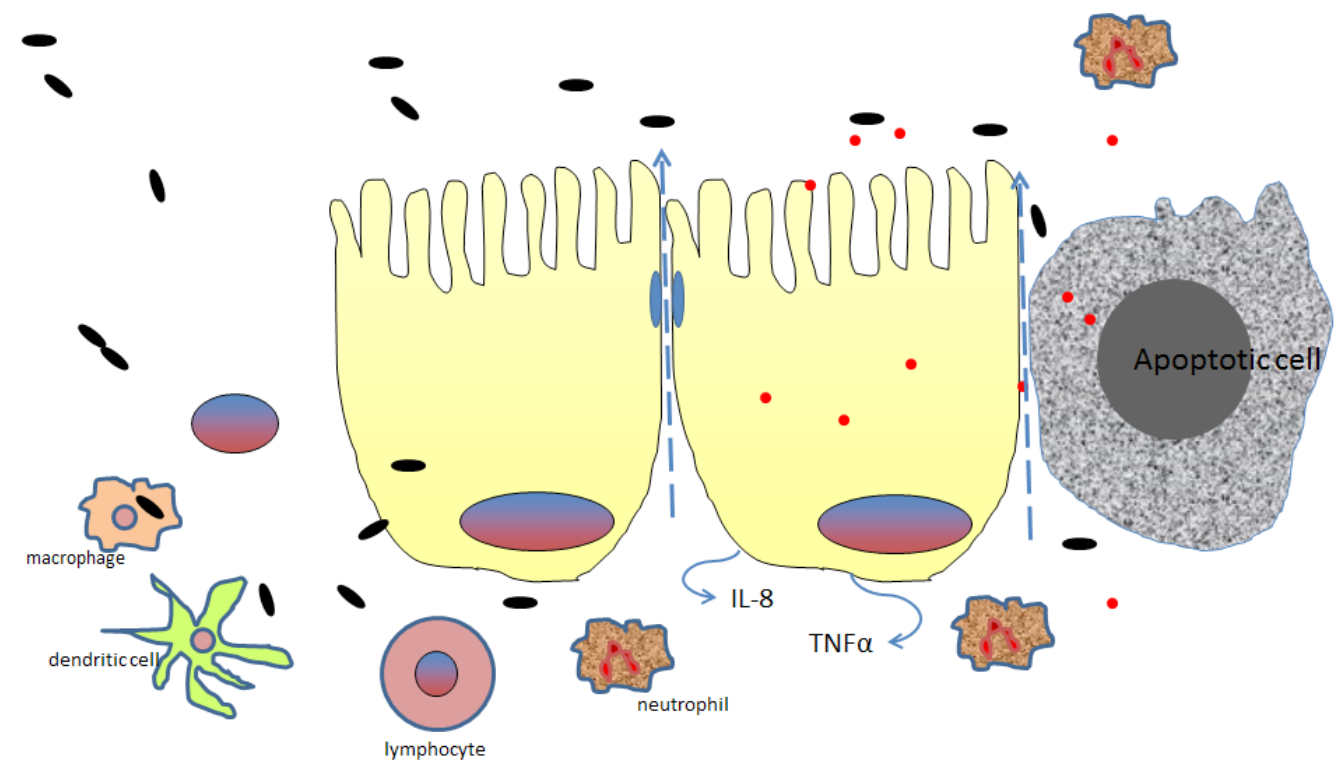

Figure 30.3 - Destruction of the epithelium by pathogens or their products. Bacteria gain entrance into the mucosa via " $M$ cells" which are specialized cells overlying immune cells like macrophages. Other bacteria secrete cytotoxins which disrupt the cytoskeleton, loosen tight junctions and induce apoptosis. The leaky epithelium facilitate ion and water secretion and importantly, access of the bacteria and their products to the immune cells in the lamina propia, furthering local inflammation and injury and systemic spread.

\subsubsection{BACTERIAL INVASION OF THE EPITHELIUM}

Certain pathogens invade and cause destruction of the intestinal epithelium. Bacteria like enteroinvasive E. coli (EIEC) and Shigella are able to penetrate the epithelium thru "M" cells (Figure 30.3). M cells are specialized cells overlying the Peyer's patches or lymphoid follicles ${ }^{22}$. These cells sample particles from the gut and serve as entry point for invasive bacteria as well. From the M cells, bacteria gain entry into macrophages and eventually, to the basolateral side of other epithelial cells. Bacteria multiply intracellularly and induce release of mediators of inflammation, promoting recruitment of inflammatory cells such as neutrophils and monocytes ${ }^{23}$. The inflammatory response result to destabilization of the epithelial barrier, further enhancing bacterial entry across the epithelium. Infected cells undergo apoptosis (programmed cell death) while bacteria spread to other cells. Pathogens like EPEC, Shigella, and Salmonella also alter proteins of the tight junctions, which are the main player in the maintenance of epithelial integrity. 


\subsubsection{CYTOTOXIC AND ENTEROTOXIC EFFECTS}

Enterohemorrhagic E. coli (EHEC)-Shiga toxin-producing E. coli (STEC) has cytotoxins or verotoxins that mediate not only secretion and mucosal injury locally but gain access to the circulation and cause endothelial damage resulting to hemolytic-uremic syndrome (HUS) ${ }^{24}$. The Shiga toxins, Stx 1 and Stx 2 are encoded in bacteriophages, which are induced under stressors, such as antibiotic exposure $^{25,26}$. The toxins that are released bind to receptors in the epithelium, get internalized and inactivate $28 \mathrm{~S}$ ribosomal RNA, thereby inhibiting protein synthesis ${ }^{27}$. In HUS, patients develop microangiopathic hemolytic anaemia characterized by the appearance of schistocytes in the peripheral smear, thrombocytopenia (low platelets) and azotemia (increased creatinine). Other organs, such as the kidneys, can be involved with ischemia from vascular thrombosis. Typically, diarrhea is hemorrhagic but relatively non-inflammatory ${ }^{28}$. Similar to EPEC, EHEC strains are also capable of inducing an attaching-effacing effect on the enterocytes ${ }^{29}$.

Clostridium difficile colonization and infection is precipitated by the disruption of the intestinal microbiota. The bacteria secrete toxin A (TcdA) and toxin B $(\mathrm{TcdB})$ that glucosylate small GTPases family of proteins (Rho, Rac, Cdc42) ${ }^{30,31}$. Inactivation of these GTP-binding proteins leads to disruption of the actin cytoskeleton, loosening of the tight junctions and apoptosis of the intoxicated cells ${ }^{32}$. TcdA and IL-8, one of the cytokines produced by epithelial cells in the presence of C. difficile toxins, iare a potent chemoattractants, thereby, facilitating migration of inflammatory cells such neutrophils and monocytes ${ }^{33}$. Furthermore, TcdA induces expression of cyclo-oxygenase 2, leading to increased prostaglandin E2 production ${ }^{34}$. Substance $\mathrm{p}$, a small peptide associated with enteric neurons, has also been noted to be increased during intoxication ${ }^{35}$.

\subsection{OTHER MECHANISMS}

Case 3. A 43 year old gentleman was admitted to the hospital because of diarrhea. His medical history is significant for Crohn's disease. One week prior to admission, he was prescribed amoxicillin-clavulanate for tooth abscess. His stool was described as voluminous and positive for WBC and occult blood.

There are many non-infectious causes of diarrhea. Each etiologic cause may have one or more mechanisms involved, whether known or unknown. It is important to recognize other factors that may contribute to the development of loose bowel movements. In general, anything that affect the activity of the ion or solute transport channels, integrity of the absorptive microvilli, cytoskeleton and tight 
junctions, and motility of the intestinal tract can lead to diarrhea. Furthermore, any one factor or pathogen may attack more than one aspect of gut physiology to synergistically lead to diarrhea.

\subsection{DRUGS}

The gastrointestinal mucosa is intimately associated with a local community of diverse organisms (intestinal microbiota). The mucosa continuously sample the contents of the intestinal lumen and mount local defenses to confine the microbiota to the gut ${ }^{36}$. These enteric organisms not only compete against colonization with potentially damaging pathogen, such as C. difficile, but also modulate the development and response of epithelial immune system ${ }^{37,38}$. Antibiotics, can cause diarrhea by alteration of the intestinal microbial flora, thereby, disturbing the symbiotic relationship between the host cells and commensal organisms. Although C. difficile is the most common known cause of antibiotic-associated diarrhea (AAD), it only accounts for $20-30 \%$ of the cases. It is possible that there are other pathogens causing $\mathrm{AAD}$ and that the microbial disruption itself may cause physiological disturbances in the intestinal mucosa leading to diarrhea.

Drugs can cause diarrhea by other various mechanisms ${ }^{39}$. Osmotic diarrhea is caused by non-absorbable solutes that are trapped in the lumen. Magnesium-containing antacids and laxatives are examples. However, prostaglandin E2 has also been noted to be increased in the stool during Mg intake ${ }^{40}$. Carbohydrate-induced diarrhea from lactulose (used for constipation and hepatic encephalopathy), fructose (from fruit juices), sorbitol and mannitol (from sugar-free candies) may also occur. Hypertonic enteral feeding will, likewise, cause osmotic diarrhea. The antidiabetic medication-acarbose, is an example of alpha-glucosidase inhibitors that prevent the breakdown of carbohydrates into monosaccharides and is associated with the development of diarrhea in up to $30 \%$ of patients ${ }^{41}$. The colonic bacteria break down undigested starch to butyrate, which in turn upregulates PGE2 ${ }^{42}$.

Similar to enteric pathogens and toxins, some drugs may also cause secretory diarrhea by altering ion or solute transport. Digoxin, by inhibiting the cardiac $\mathrm{Na}^{+} \mathrm{K}^{+}$-ATPase pump may also inhibit, often at supratherapeutic level, the same ion channel in the intestinal mucosa ${ }^{41}$. The azo compound-olsalazine, and perhaps, similar to sulfasalazine and mesalazine, which is used for inflammatory bowel disease, may cause diarrhea by stimulation of the $\mathrm{HCO}_{3}{ }^{-}$and $\mathrm{Cl}^{-}$secretion in the ileum ${ }^{43}$. Theophylline, a phosphodiesterase inhibitor, and misoprostol, a prostaglandin analogue, cause diarrhea by increasing cAMP levels, thereby, opening $\mathrm{Cl}^{-}$channels and enhancing secretion. Prostaglandins also induce diarrhea 
by altering mucosal permeability and motility. Similarly, laxatives induce diarrhea by affecting ion/solute transport and/or intestinal motility. Other drugs that cause secretory diarrhea include calcitonin (used to treat hypercalcemia and osteoporosis) and colchicine (used to treat gout; can also cause diarrhea by inhibiting microtubule formation and thus, interfering with migration of enterocytes from the crypt to the villus $)^{44,45}$.

Inflammatory diarrhea may occur from the drug-induced disruption of the intestinal epithelium causing increased intestinal permeability. Furthermore, induction of inflammation can result from bacterial or toxin translocation across the damaged epithelium. Stimulation of apoptosis and/or inhibition of cell proliferation have been reported in the use of non-steroidal anti-inflammatory drugs (NSAID), immunosuppressive agents and chemotherapeutic drugs (such as $5-\mathrm{FU})^{46}$.

Disordered motility is one of the most recognized effects of some medications. Macrolide antibiotics, especially erythromycin, can mimic the effect of motilin, a peptide hormone that is a potent contractile agent. The beta-lactamase inhibitor, clavulanate, has been shown to increase motility and duration and amplitude of contractions in human small intestines during nocturnal fasting ${ }^{47}$. The synthetic thyroid hormone, levothyroxine (used to treat hypothyroidism), similar to hyperthyroidism, also accelerates intestinal transit ${ }^{48}$.

\subsection{GASTRO-INTESTINAL AND SYSTEMIC DISEASES}

Underlying gut abnormalities and systemic illnesses, in addition to the drugs used to treat these, can cause diarrhea directly or indirectly. Mucosal disruption and inflammation from inflammatory bowel disease (Crohn's disease or ulcerative colitis), ischemic colitis, microscopic colitis (may be drug-induced also), radiation colitis and diverticulitis are examples. Alteration of ion channel transport and increased generation of intracellular second messengers (cAMP, cGMP, $\mathrm{Ca}^{++}$) can be induced by inflammatory cytokines. Decreased in absorptive microvilli consequently causes reduction of mucosa-associated digestive enzymes and ion or solute channels, such as DRA, NHE and SGLT1, as discussed above. Likewise, intestinal neoplasia, such as colon carcinoma, adenoma or lymphoma, may present with loose stool (watery, inflammatory or bloody) from the same mechanisms. Surgical resection of a diseased section of the intestinal tract can lead to "short bowel syndrome", a malabsorptive state from inability to absorb adequate nutrients, electrolytes and water and also, loss of gut hormonal production causing altered motility ${ }^{49}$. The pathophysiologic basis of the altered bowel movement ob- 
served in irritable bowel syndrome is still unclear although low grade intestinal inflammation as evidenced by increased T-lymphocytes and mast cells has been recently implicated ${ }^{50}$.

Endocrinopathies, such as diabetes and hyperthyroidism, can also manifest as diarrhea. Autonomic neuropathy in diabetes mellitus can affect the gastro-intestinal tract causing disordered motility ${ }^{51}$. Increased thyroid hormone levels in thyrotoxicosis, similar to intake of excess levothyroxine, can cause increased intestinal motility. Neuroendocrine neoplasias like gastrinoma, VIPoma, mastocytosis, carcinoid syndrome and medullary carcinoma of the thyroid all can cause diarrhea by their local effects in the gut as well. Sepsis and septic shock are often complicated by diarrhea. Decreased intestinal perfusion, hypoalbuminemia and cellular derangements; parenteral or enteral feedings; and drugs administered are all contributing factors to the development of increased secretion, malabsorption or increased gut motility.

Local intestinal and systemic diseases may also result to small intestinal bacterial overgrowth (SIBO). SIBO is defined as an increased in the number of bacteria in the upper intestinal tract. Achlorhydria, pancreatic insufficiency, immunodeficiency syndromes, anatomical abnormalities in the small intestines - whether from local disease or surgical procedures, and motility disorders all can lead to $\mathrm{SIBO}^{52}$. Production of bacterial toxic agents including ammonia, D-lactate, ethanol or peptidoglycans, have been implicated in the pathogenesis. Induction of mucosal inflammation, ulceration and villous atrophy has been observed in patients with SIBO.

\subsection{SUMMARY}

The mechanisms involved in the development of diarrhea depend on the etiologic causes, which could be multi-factorial (Figure 30.4). Often, disturbances in the enteric or systemic immune, endocrine and/or nervous systems causing either or a combination of net increased in ion/solute secretion, decreased absorption of ion/solute or nutrients, dysregulated motility and/or alteration of the intestinal microbiome can lead to diarrhea. Understanding the specific mechanisms and addressing the underlying causes are key to the control of diarrhea. 


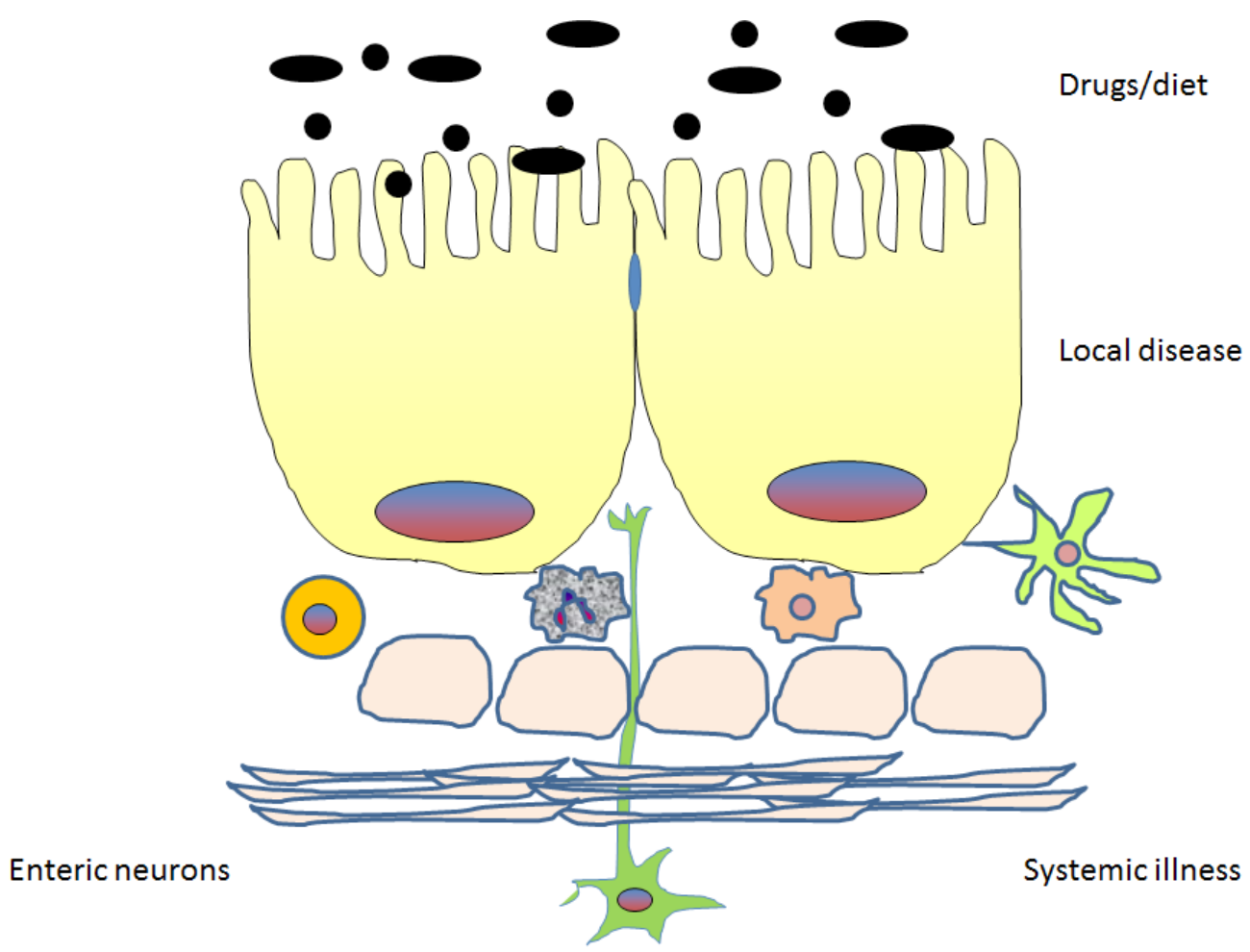

Figure 30.4 - Local and systemic factors contribute to the development of diarrhea. The intestinal tract is a delicate balance of epithelial, immune, enteric, and muscular function and mucosal commensal flora which are, in turn, affected by local intestinal and systemic health and exogenous factors like drugs and diet. Any perturbation of this balance may cause diarrhea.

\section{REFERENCES}

1. TALLEY, N. J.; WEAVER, A. L.; ZINSMEISTER, A. R.; MELTON, L. J.; III. Self-reported diarrhea: what does it mean? Am. J. Gastroenterol. 89(8): 1160-1164, 1994.

2. WENZL, H. H.; FINE, K. D.; SCHILLER, L. R.; FORDTRAN, J. S. Determinants of decreased fecal consistency in patients with diarrhea. Gastroenterology. 108(6): 1729-1738, 1995.

3. BARRETT, K. E. Water and Electrolyte Absorption. In: BARRETT, K. E. (ed.). Gastrointestinal Physiology. The McGraw Hill Companies, 2006. 
4. PRESTON, G. M.; AGRE, P. Isolation of the cDNA for erythrocyte integral membrane protein of 28 kilodaltons: member of an ancient channel family. Proc. Natl. Acad. Sci. USA. 88(24): 11110-11114, 1991.

5. ALCANTARA, W. C.; DESTURA, R. V.; SEVILLEJA, J. E. et al. Detection of epithelial-cell injury, and quantification of infection, in the HCT-8 organoid model of cryptosporidiosis. J. Infect. Dis. 198(1): 143-149, 2008.

6. KIRK, K. L.; HALM, D. R.; DAWSON, D. C. Active sodium transport by turtle colon via an electrogenic Na-K exchange pump. Nature. 287(5779): 237-239, 1980.

7. RIORDAN, J. R.; ROMMENS, J. M.; KEREM, B. ET AL. Identification of the cystic fibrosis gene: cloning and characterization of complementary DNA. Science. 245(4922): 1066-1073, 1989.

8. SHARP, G. W.; HYNIE, S. Stimulation of intestinal adenyl cyclase by cholera toxin. Nature. 229(5282): 266-269, 1971.

9. GLENN, G. M.; FRANCIS, D. H.; DANIELSEN, E. M. Toxin-mediated effects on the innate mucosal defenses: implications for enteric vaccines. Infect. Immun. 77(12): 5206-5215, 2009.

10. HOdSON, C. A.; AMbrogi, I. G.; SCOTT, R. O.; MOHLER, P. J.; MILGRAM, S. L. Polarized apical sorting of guanylyl cyclase $\mathrm{C}$ is specified by a cytosolic signal. Traffic. 7(4): 456-464, 2006.

11. SCHULZ, S.; GREEN, C. K.; YUEN, P. S.; GARBERS, D. L. Guanylyl cyclase is a heat-stable enterotoxin receptor. Cell. 63(5): 941-948, 1990.

12. BASU, N.; ARSHAD, N.; VISWESWARIAH, S. S. Receptor guanylyl cyclase $\mathrm{C}$ (GC-C): regulation and signal transduction. Mol. Cell Biochem. 334(1-2): 67-80, 2010.

13. TAKAHASHI, A.; SATO, Y.; SHIOMI, Y. et al. Mechanisms of chloride secretion induced by thermostable direct haemolysin of Vibrio parahaemolyticus in human colonic tissue and a human intestinal epithelial cell line. J. Med. Microbiol. 49(9): 801-810, 2000. 
14. LORROT, M.; VASSEUR, M. How do the rotavirus NSP4 and bacterial enterotoxins lead differently to diarrhea? Virol. J. 4: 31, 2007.

15. KARAKI, S. I.; KUWAHARA, A. Regulation of intestinal secretion involved in the interaction between neurotransmitters and prostaglandin E2. Neurogastroenterol. Motil. 16(Suppl 1): 96-99, 2004.

16. PETERSON, J. W.; OCHOA, L. G. Role of prostaglandins and cAMP in the secretory effects of cholera toxin. Science. 245(4920): 857-859, 1989.

17. HOGLUND, P.; HAILA, S.; SOCHA, J. et al. Mutations of the Downregulated in adenoma (DRA) gene cause congenital chloride diarrhoea. Nat. Genet. 14(3): 316-319, 1996.

18. GILL, R. K.; BORTHAKUR, A.; HODGES, K. et al. Mechanism underlying inhibition of intestinal apical $\mathrm{Cl} / \mathrm{OH}$ exchange following infection with enteropathogenic E. coli. J. Clin. Invest. 117(2): 428-437, 2007.

19. HODGES, K.; ALTO, N. M.; RAMASWAMY, K.; DUDEJA, P. K.; HECHT, G. The enteropathogenic Escherichia coli effector protein EspF decreases sodium hydrogen exchanger 3 activity. Cell Microbiol. 10(8): 1735-1745, 2008.

20. DEAN, P.; MARESCA, M.; SCHULLER, S.; PHILLIPS, A. D.; KENNY, B. Potent diarrheagenic mechanism mediated by the cooperative action of three enteropathogenic Escherichia coli-injected effector proteins. Proc. Natl. Acad. Sci. USA. 103(6): 1876-1881, 2006.

21. BEAU, I.; BERGER, A.; SERVIN, A. L. Rotavirus impairs the biosynthesis of brush-border-associated dipeptidyl peptidase IV in human enterocyte-like Caco-2/TC7 cells. Cell Microbiol. 9(3): 779-789, 2007.

22. HATHAWAY, L. J.; KRAEHENBUHL, J. P. The role of M cells in mucosal immunity. Cell Mol. Life Sci. 57(2): 323-332, 2000.

23. PARSOT, C. Shigella spp. and enteroinvasive Escherichia coli pathogenicity factors. FEMS Microbiol. Lett. 252(1): 11-18, 2005.

24. JACEWICZ, M. S.; ACHESON, D. W.; BINION, D. G. et al. Responses of 
human intestinal microvascular endothelial cells to Shiga toxins 1 and 2 and pathogenesis of hemorrhagic colitis. Infect. Immun. 67(3): 1439-1444, 1999.

25. O’BRIEN, A. D.; NEWLAND, J. W.; MILlER, S. F.; HOLMES, R. K.; SMITH, H. W.; FORMAL, S. B. Shiga-like toxin-converting phages from Escherichia coli strains that cause hemorrhagic colitis or infantile diarrhea. Science. 226(4675): 694-696, 1984.

26. ZHANG, X.; MCDANIEL, A. D.; WOLF, L. E.; KEUSCH, G. T.; WALDOR, M. K.; ACHESON, D. W. Quinolone antibiotics induce Shiga toxin-encoding bacteriophages, toxin production, and death in mice. J. Infect. Dis. 181(2): 664-670, 2000.

27. SANDVIG, K.; BERGAN, J.; DYVE, A. B.; SKOTLAND, T.; TORGERSEN, M. L. Endocytosis and retrograde transport of Shiga toxin. Toxicon. 56(7): 1181-1185, 2010.

28. IIDA, T.; NAKA, A.; SUTHIENKUL, O.; SAKAUE, Y.; GUERRANT, R. L.; HONDA, T. Measurement of fecal lactoferrin for rapid diagnosis of enterohemorrhagic Escherichia coli infection. Clin. Infect. Dis. 25(1): 167, 1997.

29. PERNA, N. T.; MAYHEW, G. F.; POSFAI, G. et al. Molecular evolution of a pathogenicity island from enterohemorrhagic Escherichia coli O157:H7. Infect. Immun. 66(8): 3810-3817, 1998.

30. JUST, I.; SELZER, J.; WILM, M.; VON EICHEL-STREIBER, C.; MANN, M.; AKTORIES, K. Glucosylation of Rho proteins by Clostridium difficile toxin B. Nature. 375(6531): 500-503, 1995.

31. JUST, I.; WILM, M.; SELZER, J. et al. The enterotoxin from Clostridium difficile (ToxA) monoglucosylates the Rho proteins. J. Biol. Chem. 270(23): 13932-13936, 1995.

32. GENTH, H.; DREGER, S. C.; HUELSENBECK, J.; JUST, I. Clostridium difficile toxins: more than mere inhibitors of Rho proteins. Int. J. Biochem. Cell Biol. 40(4): 592-597, 2008.

33. VOTH, D. E.; BALLARD, J. D. Clostridium difficile toxins: mechanism of 
action and role in disease. Clin. Microbiol. Rev. 18(2): 247-263, 2005.

34. ALCANTARA, C.; STENSON, W. F.; STEINER, T. S.; GUERRANT, R. L. Role of inducible cyclooxygenase and prostaglandins in Clostridium difficile toxin A-induced secretion and inflammation in an animal model. J. Infect. Dis. 184(5): 648-652, 2001.

35. MANTYH, C. R.; PAPPAS, T. N.; LAPP, J. A. et al. Substance P activation of enteric neurons in response to intraluminal Clostridium difficile toxin $\mathrm{A}$ in the rat ileum. Gastroenterology. 111(5): 1272-1280, 1996.

36. SLACK, E.; HAPFELMEIER, S.; STECHER, B. et al. Innate and adaptive immunity cooperate flexibly to maintain host-microbiota mutualism. Science. 325(5940): 617-620, 2009.

37. KELLY, D.; CAMPBELL, J. I.; KING, T. P. et al. Commensal anaerobic gut bacteria attenuate inflammation by regulating nuclear-cytoplasmic shuttling of PPAR-gamma and RelA. Nat. Immunol. 5(1): 104-112, 2004.

38. MAZMANIAN, S. K.; LIU, C. H.; TZIANABOS, A. O.; KASPER, D. L. An immunomodulatory molecule of symbiotic bacteria directs maturation of the host immune system. Cell. 122(1): 107-118, 2005.

39. ABRAHAM, B.; SELLIN, J. H. Drug-induced diarrhea. Curr. Gastroenterol. Rep. 9(5): 365-372, 2007.

40. DONOWITZ, M.; ROOD, R. P. Magnesium hydroxide: new insights into the mechanism of its laxative effect and the potential involvement of prostaglandin E2. J. Clin. Gastroenterol. 14(1): 20-26, 1992.

41. RATNAIKE, R. N.; JONES, T. E. Mechanisms of drug-induced diarrhoea in the elderly. Drugs Aging. 13(3): 245-253, 1998.

42. KAST, R. E. Acarbose related diarrhea: increased butyrate upregulates prostaglandin E. Inflamm. Res. 51(3): 117-118, 2002.

43. KLES, K.A.; VAVRICKA, S. R.; TURNER, J. R.; MUSCH, M. W.; HANAUER, S. B.; CHANG, E. B. Comparative analysis of the in vitro prosecretory effects of balsalazide, sulfasalazine, olsalazine, and mesalamine in rabbit distal 
ileum. Inflamm. Bowel Dis. 11(3): 253-257, 2005.

44. MOLAD, Y. Update on colchicine and its mechanism of action. Curr. Rheumatol. Rep. 4(3): 252-256, 2002.

45. GRAY, T. K.; BIEBERDORF, F. A.; FORDTRAN, J. S. Thyrocalcitonin and the jejunal absorption of calcium, water, and electrolytes in normal subjects. J. Clin. Invest. 52(12): 3084-3088, 1973.

46. PARFITT, J. R.; DRIMAN, D. K. Pathological effects of drugs on the gastrointestinal tract: a review. Hum. Pathol. 38(4): 527-536, 2007.

47. CARON, F.; DUCROTTE, P.; LEREBOURS, E.; COLIN, R.; HUMBERT, G.; DENIS, P. Effects of amoxicillin-clavulanate combination on the motility of the small intestine in human beings. Antimicrob. Agents. Chemother. 35(6): 1085-1088, 1991.

48. WEGENER, M.; WEDMANN, B.; LANGHOFF, T.; SCHAFFSTEIN, J.; ADAMEK, R. Effect of hyperthyroidism on the transit of a caloric solidliquid meal through the stomach, the small intestine, and the colon in man. J. Clin. Endocrinol. Metab. 75(3): 745-749, 1992.

49. DONOHOE, C. L.; REYNOLDS, J. V. Short bowel syndrome. Surgeon. 8(5): 270-279, 2010.

50. ORTIZ-LUCAS, M.; SAZ-PEIRO, P.; SEBASTIAN-DOMINGO, J. J. Irritable bowel syndrome immune hypothesis. Part one: the role of lymphocytes and mast cells. Rev. Esp. Enferm. Dig. 102(11): 637-647, 2010.

51. SHAKIL, A.; CHURCH, R. J.; RAO, S. S. Gastrointestinal complications of diabetes. Am. Fam. Physician. 77(12): 1697-1702, 2008.

52. BURES, J.; CYRANY, J.; KOHOUTOVA, D. et al. Small intestinal bacterial overgrowth syndrome. World J. Gastroenterol. 16(24): 2978-2990, 2010.

53. KEELY, S. J.; BARRETT, K. E. Regulation of chloride secretion. Novel pathways and messengers. Ann. N. Y. Acad. Sci. 915: 67-76, 2000. 
